\title{
The impact of environmental cadmium exposure on type 2 diabetes risk: a protocol for an overview of systematic reviews
}

Julia Hildebrand ${ }^{1,2}$, Swarni Thakar ${ }^{1,2}$, Tonya-Leah Watts ${ }^{1,2}$, Laura Banfield ${ }^{3}$, Lehana Thabane ${ }^{4,5,6,7}$, Joseph Macri ${ }^{8}$, Stephen Hill ${ }^{9}$ and M. Constantine Samaan ${ }^{1,2,4,10^{*}}$ [D

\begin{abstract}
Background: Type 2 diabetes mellitus (T2DM) is a worldwide epidemic, and while its etiology is polygenic, the role of environmental contaminant exposure in T2DM pathogenesis is of increasing importance. However, the evidence presented in systematic reviews on the relationship between cadmium exposure and T2DM development is inconsistent. This overview aims to assess existing evidence from systematic reviews linking cadmium exposure to T2DM and select metabolic disorders in humans.

Methods: Searches will be conducted in Medline, Embase, Web of Science, GEOBASE, BIOSIS Previews, and Cochrane Database of Systematic Reviews. Two reviewers (J.H and S.T.) will independently complete screening, data abstraction, risk of bias evaluation, and quality assessment. The primary outcome will be the association between cadmium exposure and T2DM prevalence. Secondary outcomes will include prediabetes, obesity, dyslipidemia, hypertension, and non-alcoholic fatty liver disease. We will perform a meta-analysis if two or more studies assess similar populations, utilize analogous methods, have related study designs, and evaluate similar outcomes.

Discussion: This overview will assess current evidence from systematic reviews for the association between cadmium exposure and risk of T2DM and other metabolic morbidities. This overview may be helpful for policymakers and healthcare teams aiming to mitigate T2DM risk in populations at risk of cadmium exposure.
\end{abstract}

Systematic review registration: PROSPERO CRD42019125956

Keywords: Cadmium, Type 2 diabetes mellitus, Obesity, Dyslipidemia, Prediabetes, Hypertension, Non-alcoholic fatty liver disease, Overview of systematic reviews, Meta-analysis, Protocol

\section{Background}

Over the past few decades, type 2 diabetes mellitus (T2DM) has become a worldwide epidemic [1], with 451 million adults estimated to have T2DM as of 2017 [1]. While obesity is considered the T2DM epidemic's main driver, T2DM pathogenesis is complex and is not fully understood [2].

\footnotetext{
* Correspondence: samaanc@mcmaster.ca

${ }^{1}$ Department of Pediatrics, McMaster University, Hamilton, Ontario, Canada 2Division of Pediatric Endocrinology, McMaster Children's Hospital, Hamilton, Ontario, Canada

Full list of author information is available at the end of the article
}

One emerging factor implicated in T2DM risk is environmental exposure to endocrine-disrupting chemicals (EDCs) [3-5]. These compounds alter endocrine function by binding to hormone receptors and act as agonist or antagonist signaling molecules or by interfering with hormonal signaling pathways [4, 6-9]. These molecules encompass a vast array of natural and man-made compounds that may exert powerful metabolic effects.

Cadmium $(\mathrm{Cd})$ is a naturally occurring soft metal with endocrine-disrupting properties [6]. It has several industrial uses, including metal mining and the manufacturing of protective steel plating, pigments, and rechargeable batteries. Additional sources of exposure also include

(C) The Author(s). 2019 Open Access This article is distributed under the terms of the Creative Commons Attribution 4.0 International License (http://creativecommons.org/licenses/by/4.0/), which permits unrestricted use, distribution, and 
phosphate fertilizers, waste disposal, pulp and paper production, and sewage treatment by-products $[6,10]$. The adverse effects $\mathrm{Cd}$ poses to human, wildlife, and environmental health are significant, and it is classified as a carcinogen by the European Chemicals Agency [11] and as a hazardous substance and air pollutant by the Environmental Protection Agency and in the Clean Water Act and Clean Air Act in the United States[10, 12, 13]. Cd is not involved in normal human physiology, and its adverse health effects range from renal damage, cancer, osteomalacia, and osteoporosis with low-level chronic exposure $[10,14-18]$ to severe pulmonary damage or even death with acute high-dose exposure [10, 19].

While in-vivo and in-vitro studies suggest a link between $\mathrm{Cd}$ exposure and diabetes [20-26], human studies are limited and have yielded conflicting evidence to verify this relationship [27-34].

The purpose of this overview is to synthesize current evidence from systematic reviews for the association between $\mathrm{Cd}$ exposure and risk of T2DM and other metabolic outcomes in humans.

\section{Research questions}

Primary

In the general population, is environmental cadmium exposure associated with increased T2DM risk?

\section{Secondary}

In the general population, is cadmium exposure associated with obesity, prediabetes, dyslipidemia, hypertension, and non-alcoholic fatty liver disease (NAFLD)?

\section{Methods}

This protocol was developed following the Preferred Reporting Items for Systematic Review and MetaAnalysis Protocols (PRISMA-P) statement guidelines [35] (Additional file 1).

\section{Literature search}

The search strategy will be developed by a Health Sciences Librarian with expertise in systematic review search methodologies. To identify systematic reviews relevant to the research question, searches will be conducted in Medline, Embase, Web of Science, BIOSIS Previews, GEOBASE (Geoscience Literature Research Database) [36], and Cochrane Database of Systematic Reviews. A sample Medline search strategy is presented in Table 1. Search strategies will include databasespecific terms and filters pertaining to systematic reviews, meta-analyses, cadmium, humans, T2DM, and the metabolic abnormalities listed above. Reference lists of accepted articles and relevant non-systematic reviews will be screened for additional studies.
We will use Endnote X7 [37] to collect identified articles and de-duplicate them before exporting unique records to an Excel spreadsheet.

\section{Inclusion criteria}

Systematic reviews that synthesize evidence for the association between $\mathrm{Cd}$ exposure and diabetes using observational studies with prospective/retrospective cohort, cross-sectional, and case-control study designs will be considered for this review. A systematic review is defined as a review that (1) has a detailed, comprehensive, and systematic search strategy, (2) contains specific inclusion/exclusion criteria and uses systematic review methodology, (3) attempts to synthesize all relevant studies on the topic, and (4) may or may not include a meta-analysis [38].

The population of interest include both males and females in the general population with no restrictions on age, smoking status, ethnicity, geographical location, setting, or timing of publication. The exposure of interest is $\mathrm{Cd}$ that is measured in blood or urine samples, and all $\mathrm{Cd}$ exposure sources will be considered including smoking, food, water, air, soil, industrial, or accidental exposure. Our primary outcome is T2DM prevalence.

While T2DM accounts for around 90\% of diabetes cases in adults globally [1], if a review does not differentiate between type 1 and 2 diabetes, we will reach out to the principal investigators to seek clarification on the exact type of diabetes in the study population in question. Our a priori assumption is that the published data are mainly relevant to T2DM, while acknowledging the limitation if the exact type of diabetes is not reported.

\section{Exclusion criteria}

We will exclude abstracts of systematic reviews with no published full-text papers and non-systematic narrative literature reviews. We will also exclude systematic reviews not published in English, those reporting only on gestational or type 1 diabetes, and non-human or invitro studies, if retrieved in the literature searches.

\section{Study selection}

Two independent reviewers (J.H. and S.T.) will screen titles and abstracts of each record, followed by full-text screening. Reviewers will accept records based on their relevance to the research question and the eligibility criteria. After each stage, the reviewers will discuss discrepancies to reach consensus. To resolve persistent disagreements, a third reviewer will be consulted to make a final decision for study inclusion in the review. The kappa statistic will be calculated for study selection to test interrater reliability. We will use a PRISMA flowchart (Fig. 1) to document the screening process and report this in the full review $[39,40]$. 
Table 1 MEDLINE search strategy

\begin{tabular}{|c|c|}
\hline$\#$ & Searches \\
\hline 1 & Cadmium/ \\
\hline 2 & exp cadmium compounds/ \\
\hline 3 & Cadmium poisoning/ \\
\hline 4 & cadmium.mp. \\
\hline 5 & or/1-4 \\
\hline 6 & exp diabetes mellitus, type 2/ \\
\hline 7 & $\begin{array}{l}\text { ((Type } 2 \text { or type } \| \text { or non-insulin or non-insulin or adult } \\
\text { onset or matur* onset) adj3 diabet*).mp. }\end{array}$ \\
\hline 8 & T2DM.mp. \\
\hline 9 & T2D.mp. \\
\hline 10 & NIDDM.mp. \\
\hline 11 & 6 or 7 or 8 or 9 or 10 \\
\hline 12 & $\begin{array}{l}\text { Overnutrition/or obesity/or obesity, abdominal/or obesity, } \\
\text { morbid/or pediatric obesity/ }\end{array}$ \\
\hline 13 & obes*.mp. \\
\hline 14 & Overweight/ \\
\hline 15 & (Overweight or overweight or excess* weight).mp. \\
\hline 16 & Overnutrition.mp. \\
\hline 17 & (Weight adj2 (gain* or increase* or excess*)).mp. \\
\hline 18 & BMl.mp. \\
\hline 19 & Body mass index/or skinfold thickness/or waist-hip ratio/ \\
\hline 20 & Body mass index.mp. \\
\hline 21 & Waist circumference*.mp. \\
\hline 22 & Waist to hip ratio*.mp. \\
\hline 23 & Waist hip ratio*.mp. \\
\hline 24 & Waist to height.mp. \\
\hline 25 & Waist height.mp. \\
\hline 26 & Skinfold thickness/ \\
\hline 27 & Skinfold*.mp. \\
\hline 28 & Insulin resistance/ or metabolic syndrome/ \\
\hline 29 & (Insulin adj2 (resistan* or sensitiv*)).mp. \\
\hline 30 & Metabolic syndrom*.mp. \\
\hline 31 & Exp lipid Metabolism/ \\
\hline 32 & Lipid*.mp. \\
\hline 33 & (Lipogenesis or lypolysis or lipoylation).mp. \\
\hline 34 & Exp glucose/ \\
\hline 35 & glucose.mp. \\
\hline 36 & Insulin/ \\
\hline 37 & Hypertension/ \\
\hline 38 & Hypertens*.mp. \\
\hline 39 & or/12-37 \\
\hline 40 & 11 or 39 \\
\hline 41 & 5 and 40 \\
\hline 42 & Remove duplicates from 41 \\
\hline 43 & 5 and 11 \\
\hline
\end{tabular}

Table 1 MEDLINE search strategy (Continued)

\begin{tabular}{ll}
\hline$\#$ & Searches \\
\hline 44 & Systematic review*.mp. \\
45 & Meta-Analysis as topic/or "review literature as topic"/ \\
46 & Meta-analys*.mp. \\
47 & or/44-46 \\
48 & 43 and 47 \\
\hline
\end{tabular}

Following screening, data abstraction for eligible fulltext articles and their included primary studies will be performed. This will be followed by risk of bias (ROB) and quality assessments [41, 42].

\section{Outcomes}

Primary

The primary outcome is the association of $\mathrm{Cd}$ exposure with T2DM prevalence. We will maintain a broad approach for identifying T2DM to account for varying definitions present within included systematic reviews. T2DM may be defined biochemically using national guidelines of fasting or random plasma glucose, oral glucose tolerance test (OGTT), or HbA1c [43, 44]. In addition, T2DM may be identified through diabetes registries or databases, self- or physician-reported diagnosis, or antidiabetic medication use [45].

\section{Secondary}

Adverse metabolic effects linked to $\mathrm{Cd}$ exposure will be assessed including:

1. Prediabetes, including impaired fasting glucose and impaired glucose tolerance, is defined by fasting or random plasma glucose, OGTT, or HbA1c using national guideline cutoffs [43, 44]. Alternatively, self-reported or physician-reported diagnosis, hospital database diagnosis, or specifically reported prediabetes-related medication or intervention use may be used as a marker of prediabetes.

2. Overweight or obesity is defined using body mass index (BMI) z-score on 85-94.9th percentile indicating overweight and $\geq 95$ th percentile for obesity in children [46] and BMI $25-29.9 \mathrm{~kg} / \mathrm{m}^{2}$ indicating overweight and $\geq 30 \mathrm{~kg} / \mathrm{m}^{2}$ indicating obesity in adults [47].

3. Dyslipidemia is assessed by detecting abnormal levels of total cholesterol, high-density lipoprotein cholesterol, triglycerides, low-density lipoprotein cholesterol (measured or calculated), non-highdensity lipoprotein cholesterol, or apolipoprotein A and $\mathrm{B}$ measured in, or converted to, $\mathrm{mmol} / \mathrm{L}$ [48].

4. Hypertension is defined in children as systolic and/ or diastolic blood pressure (BP) $\geq 95$ th percentile according to age- and sex-specific BP centiles and 


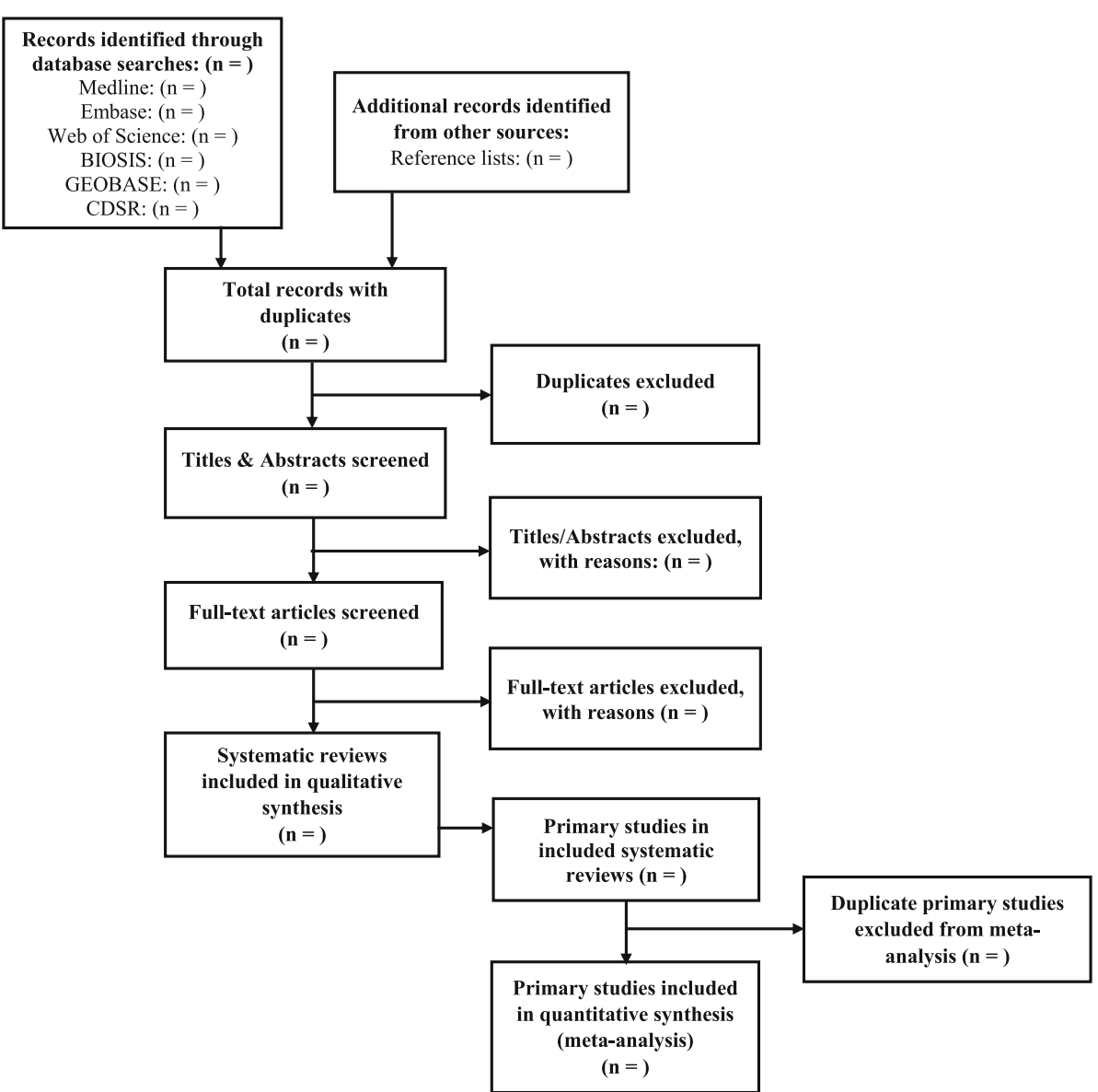

Fig. 1 PRISMA Flow Diagram

reported in millimeters of mercury (mmHg) [49]. Hypertension will be defined in adults using cutoffs in $\mathrm{mmHg}$ from the American College of Cardiology/ American Heart Association guidelines [50].

5. NAFLD is defined by elevated transaminases which are threefold higher than the normal reference range of the reported result or documented on liver ultrasound or both $[43,51]$.

\section{Data collection}

The two independent reviewers (J.H. and S.T.) will collect the data, and kappa will be calculated for interrater reliability. We will develop and pilot a data abstraction form that includes data on authors' names, journal name, publication date, study setting, country, research question/aims, search strategy details, inclusion and exclusion criteria, and funding agency if applicable. We will also collect data on the population including sample size and participant characteristics including age, sex, ethnicity, BMI, diabetes definition, reports of overweight status, and number of T2DM cases and controls if available, number of included primary studies and their study designs, methods for quality assessment of primary studies, Cd exposure and measurement, and conclusions. We will also extract the pooled effect estimates along with 95\% confidence interval (CI) and the $I^{2}$ values and chi-square test $p$ value if reported for heterogeneity across individual studies.

Furthermore, we will collect data from primary studies in each systematic review including authors' names, publication year, study design, population characteristics (ethnicity, age, sex), country, diabetes definition, participant inclusion and exclusion criteria, number of participants, assessment method, and data for $\mathrm{Cd}$ exposure and for each outcome. The standard mean difference and 95\% CI for the desired outcome, if available, will also be collected. If there are missing data, we will e-mail the principal investigators of the systematic reviews to determine if the data are accessible. If the data are not available to them, we will contact the authors of the primary studies from which the evidence was derived in the reported systematic reviews to ascertain if the data are available [52]. 


\section{Risk of bias and quality assessment}

Two reviewers (J.H and S.T.) will independently assess the methodological quality of systematic reviews using a revised version of the Assessment of Multiple Systematic Reviews-2 (AMSTAR-2) tool [53] (Additional file 2). AMSTAR-2 was designed for systematic reviews of intervention studies [53]. Thus, we have modified it for appropriate quality assessment of systematic reviews of observational studies (Additional file 2) based on a previously modified R-AMSTAR tool [54]. This tool consists of 14 items and is not meant to provide an overall score. Rather, authors will consider the effect of low scores for certain items on review quality and provide a high, moderate, low, or critically low overall confidence rating based on weaknesses in these critical domains [53].

$\mathrm{ROB}$ of included systematic reviews will also be assessed using the risk of bias in systematic reviews (ROBIS) tool [55]. This tool measures ROB as high, low, or unclear in four domains (study eligibility criteria, identification and selection of studies, data collection and study appraisal, and synthesis and findings) [55].

\section{Statistical analysis}

To avoid confounding from having the same primary study included in multiple systematic reviews, a metaanalysis will be conducted at the primary study level if applicable. For this process, primary studies of each review will be screened, and all duplicates will be removed. A meta-analysis will be performed if two or more primary studies with similar methods, populations, exposures, and outcomes are identified from included reviews. We will use a random effects model to account for variation in effect size among studies [56]. Dichotomous outcomes will be reported as an odds ratio and continuous outcomes as a standardized mean difference with $95 \%$ CI. As the systematic reviews in this overview would have included observational studies, we will perform our analyses based on method of $\mathrm{Cd}$ measurement and study designs including cross-sectional, case-control, or cohort studies. A meta-analysis will be performed provided that at least two studies are available under each category.

If a meta-analysis is performed, heterogeneity among included systematic reviews will be quantified using the inconsistency index $\left(I^{2}\right)$ and $p$ values from the chisquare test for homogeneity. The $I^{2}$ will be interpreted using the Cochrane Collaboration threshold [56], with a value of $>75 \%$ representing considerable heterogeneity. A chi-square test $p$ value of $<0.10$ will define statistical significance [56]. If a meta-analysis is not feasible, we will provide narrative and tabulated summaries of the data.

Several studies have demonstrated sex-specific effects of $\mathrm{Cd}$ exposure [57-62], and $\mathrm{Cd}$ exposure levels may vary based on geographic location and method of exposure. Therefore, we will perform subgroup analyses by sex and ethnicity (stratified by countries where primary studies were carried out). We will also perform a subgroup analysis for accidental/occupational exposure compared to exposure among the general population if possible and will ask investigators for unpublished data.

If considerable heterogeneity is observed, we will perform meta-regression analyses to investigate the potential bases of heterogeneity if data from ten or more studies are available [56].

If ten or more studies are identified for an outcome a sensitivity analysis will be conducted, and studies with high risk of bias and small sample size will be excluded in a separate meta-analysis to assess their impact on the results using the Review Manager Software version 5.3 (RevMan 5.3) [63]. We will also evaluate publication bias using a funnel plot and employ visual inspection and Egger's test to determine plot asymmetry using the Statistical Package for the Social Sciences (SPSS) version $25.0[64,65]$.

Results of this overview will be reported according to the Preferred Reporting Items for Systematic Reviews and Meta-Analyses (PRISMA) guidelines [39, 40]. The reasons for any protocol amendments will be documented in the full review.

\section{Discussion}

While $\mathrm{Cd}$ exposure may occur through industrial exposures or via consumption of contaminated food and water, and soil or dust contact [66], the primary source of human exposure is smoking, which almost doubles Cd body burden [10]. In non-smokers, the primary $\mathrm{Cd}$ exposure source is diet, with the largest concentrations acquired from plant foods $[10,67$, 68], liver/kidney meats, and shellfish [10, 14, 66, 69, 70]. In areas near $\mathrm{Cd}$-emitting industries, well water and rivers may also represent significant exposure sources [71].

The role of $\mathrm{Cd}$ in T2DM development remains unclear. Multiple mechanisms have been proposed including increased gluconeogenic enzyme activation, increased oxidative stress in pancreatic beta-cells, altered glucose transport in adipose and renal tissues, and altered cell-cell adhesions that can potentially lead to islet dysfunction, impaired insulin secretion, and subsequent dysglycemia [72-74]. As T2DM rates rise worldwide [75], accurately determining Cd's contribution to diabetes risk could improve decision-making regarding $\mathrm{Cd}$ use and precautions to protect at-risk populations.

One limitation of this overview is the exclusion of non-English language articles, which may exclude some additional papers. Nonetheless, this overview will clarify the association between $\mathrm{Cd}$ exposure and T2DM in the general population, help identify future research needs, and guide health policy to limit exposure if an association between $\mathrm{Cd}$ exposure and T2DM risk is confirmed. 


\section{Supplementary information}

Supplementary information accompanies this paper at https://doi.org/10. 1186/s13643-019-1246-7.

Additional file 1. PRISMA-P checklist. This checklist documents the location within this protocol of recommended items to address in a systematic review protocol.

Additional file 2. Modified AMSTAR-2 tool. This file contains a modified version of the AMSTAR-2 tool, as well as a list of the modifications made by the authors to the original tool.

\section{Abbreviations}

AMSTAR-2: Assessment of Multiple Systematic Reviews 2; BMl: Body mass index; BP: Blood pressure; Cd: Cadmium; Cl: Confidence intervals; EDC: Endocrine-disrupting chemical; HbA1c: Hemoglobin A1c; NAFLD: Nonalcoholic fatty liver disease; OGTT: Oral glucose tolerance test; PRISMA: Preferred Reporting Items for Systematic Reviews and MetaAnalyses; PRISMA-P: Preferred Reporting Items for Systematic Review and Meta-Analysis Protocols; RevMan 5.3: Review Manager Software version 5.3 ROB: Risk of bias; ROBIS: Risk of bias in systematic reviews; SPSS: Statistical Package for the Social Sciences; T2DM: Type 2 diabetes mellitus

\section{Acknowledgements}

None

\section{Authors' contributions}

MCS is the guarantor of this review. JH, ST, TLW, JM, SH, LT, LB, and MCS defined the research question. JH, ST, TLW, LB, LT, JM, SH, and MCS developed the Medline search strategy and determined inclusion and exclusion criteria. Methodological support and assessment of exposure methods and tests for this review was provided by LT, JM, SH, and MCS. JH, ST, TLW, and MCS created the first draft of the manuscript, and all authors reviewed and approved the final draft of the manuscript

\section{Funding}

Tonya-Leah Watts was funded through the Indigenous Undergraduate Student Research Scholarship award, McMaster University.

\section{Availability of data and materials \\ Not applicable.}

\section{Ethics approval and consent to participate}

Not applicable.

\section{Consent for publication}

Not applicable.

\section{Competing interests}

The authors declare that they have no competing interests.

\begin{abstract}
Author details
${ }^{1}$ Department of Pediatrics, McMaster University, Hamilton, Ontario, Canada. ${ }^{2}$ Division of Pediatric Endocrinology, McMaster Children's Hospital, Hamilton, Ontario, Canada. ${ }^{3}$ Health Sciences Library, McMaster University, Hamilton, Ontario, Canada. ${ }^{4}$ Department of Health Research Methods, Evidence, and Impact, McMaster University, Hamilton, Ontario, Canada. ${ }^{5}$ Department of Anesthesia, McMaster University, Hamilton, Ontario, Canada. ${ }^{6}$ Centre for Evaluation of Medicines, St. Joseph's Healthcare, Hamilton, Ontario, Canada. ${ }^{7}$ Biostatistics Unit, St. Joseph's Healthcare Hamilton, Hamilton, Ontario, Canada. ${ }^{8}$ Hamilton Regional Laboratory Medicine Program, Hamilton, Ontario, Canada. ${ }^{9}$ Department of Pathology and Molecular Medicine, McMaster University, Hamilton, Ontario, Canada. ${ }^{10}$ Michael G. DeGroote School of Medicine, McMaster University, Hamilton, Ontario, Canada.
\end{abstract}

Received: 5 August 2019 Accepted: 25 November 2019

Published online: 06 December 2019

\section{References}

1. IDF Diabetes Atlas. 8th ed. Brussels: International Diabetes Federation; 2017.
2. Czech MP. Insulin action and resistance in obesity and type 2 diabetes. Nature Medicine. 2017:23:804-14.

3. Kuo C, Moon K, Thayer K, Navas-Acien A. Environmental chemicals and type 2 diabetes: an updated systematic review of the epidemiologic evidence. Curr Diab Rep. 2013;13(6):831-49.

4. Gore A, Chappell V, Fenton S, Flaws J, Nadal A, Prins G, et al. Executive summary to EDC-2: the endocrine society's second scientific statement on endocrine-disrupting chemicals. Endocr Rev. 2015;36(6):593.

5. Identification of risks from exposure to endocrine-disrupting chemicals at the country level. Copenhagen: World Health Organization; 2014.

6. State of the science of endocrine disrupting chemicals - 2012. United Nations Environment Programme and the World Health Organization; 2013.

7. Colborn T, Vom Saal FS, Soto AM. Developmental effects of endocrinedisrupting chemicals in wildlife and humans. Environ Health Perspect. 1993; 101(5):378-84.

8. Tabb MM, Blumberg B. New modes of action for endocrine-disrupting chemicals. Mol Endocrinol. 2006;20(3):475-82.

9. McLachlan JA. Environmental signaling: what embryos and evolution teach us about endocrine disrupting chemicals. Endocrine Reviews. 2001;22(3):319-41.

10. Faroon O, Ashizawa A, Wright S, Tucker P, Jenkins K. Toxicological profile for cadmium. Atlanta: Agency for Toxic Substances and Disease Registry (US); 2012.

11. Cadmium - substance information - ECHA Helsinki2018. Available from: https://echa.europa.eu/substance-information/-/substanceinfo/100.028.320.

12. Federal water pollution control act 33 U.S.C. 1251 et seq. 2018.

13. Air pollution prevention and control 42 U.S.C. 7412. 2018.

14. Satarug S, Garrett SH, Sens MA, Sens DA. Cadmium, environmental exposure, and health outcomes. Environ Health Perspect. 2010; 118(2): 182-190.

15. Järup L, Alfvén T. Low level cadmium exposure, renal and bone effects-the OSCAR study. Biometals. 2004;17(5):505-9.

16. Järup L, Hellström L, Alfvén T, Carlsson MD, Grubb A, Persson B, et al. Low level exposure to cadmium and early kidney damage: the OSCAR study. Occup Environ Med. 2000:57(10):668-72.

17. Nawrot T, Plusquin M, Hogervorst J, Roels HA, Celis H, Thijs L, et al. Environmental exposure to cadmium and risk of cancer: a prospective population-based study. Lancet Oncol. 2006;7(2):119-26.

18. Alfvén T, Elinder CG, Carlsson MD, Grubb A, Hellström L, Persson B, et al. Low-level cadmium exposure and osteoporosis. J Bone Mineral Res. 2000; 15(8):1579-86.

19. Beton D, Andrews G, Davies H, Howells L, Smith G. Acute cadmium fume poisoning: five cases with one death from renal necrosis. Occup Environ Med. 1966;23(4):292-301.

20. Lei L-J, Jin T-Y, Zhou Y-F. Insulin expression in rats exposed to cadmium. Biomed Environ Sci. 2007:20(4):295-301.

21. Bell R, Early J, Nonavinakere V, Mallory Z. Effect of cadmium on blood glucose level in the rat. Toxicol Lett. 1990;54(2-3):199-205.

22. Merali Z, Singhal R. Diabetogenic effects of chronic oral cadmium administration to neonatal rats. Brit J Pharmacol. 1980:69(1):151-7.

23. Han JC, Park SY, Hah BG, Choi GH, Kim YK, Kwon TH, et al. Cadmium induces impaired glucose tolerance in rat by down-regulating GLUT4 expression in adipocytes. Arch Biochem Biophys. 2003;413(2):213-20.

24. Edwards JR, Prozialeck WC. Cadmium, diabetes and chronic kidney disease. Toxicol Appl Pharmacol. 2009;238(3):289-93

25. El Muayed M, Raja MR, Zhang X, MacRenaris KW, Bhatt S, Chen X, et al. Accumulation of cadmium in insulin-producing $\beta$ cells. Islets. 2012;4(6): 405-16.

26. Gavazzo P, Morelli E, Marchetti C. Susceptibility of insulinoma cells to cadmium and modulation by L-type calcium channels. Biometals. 2005; 18(2):131

27. Haswell-Elkins M, Imray P, Soisungwan S, Moore M, O'Dea K. Urinary excretion of cadmium among Torres Strait Islanders (Australia) at risk of elevated dietary exposure through traditional foods. J Expo Sci Environ Epidemiol. 2007:17:372-7.

28. Nie X, Ningjian W, Chen Y, Chen C, Han B, Zhu C, et al. Blood cadmium in Chinese adults and its relationships with diabetes and obesity. Environ SCi Pollut Res. 2016;23(18):18714-23.

29. Swaddiwudhipong W, Mahasakpan P, Limpatanachote P, Krintratun S. Correlations of urinary cadmium with hypertension and diabetes in persons living in cadmium-contaminated villages in northwestern Thailand: a population study. Environ Res. 2010;110(6):612-6. 
30. Moon S. Association of lead, mercury and cadmium with diabetes in the Korean population: the Korea National Health and Nutrition Examination Survey (KNHANES) 2009-2010. Diabet Med. 2013;30(4):e143-8.

31. Barregard L, Bergstrom G, Fagerberg B. Cadmium exposure in relation to insulin production, insulin sensitivity and type 2 diabetes: a cross-sectional and prospective study in women. Environ Res. 2013;121:104-9.

32. Li X, Peng Y, Gao Y, Guo W, Wang J, Liu X, et al. Association between plasma metal levels and diabetes risk: a case-control study in China. Biomed Environ Sci. 2017;30(7):482-91.

33. Feng W, Cui X, Liu C, Xiao Y, Lu W, Guo H, et al. Association of urinary metal profiles with altered glucose levels and diabetes risk: a population-based study in China. PLoS One. 2015;10(4):e0123742.

34. Afridi HI, Kazi TG, Kazi N, Jamali MK, Arain MB, Jalbani N, et al. Evaluation of status of toxic metals in biological samples of diabetes mellitus patients. Diabet Res Clin Pract. 2008:80(2):280-8.

35. Shamseer L, Moher D, Clarke M, Ghersi D, Liberati A, Petticrew M, et al. Preferred reporting items for systematic review and meta-analysis protocols (PRISMA-P) 2015: elaboration and explanation. BMJ. 2015;349:97647.

36. GEOBASE. Engineering Village, Elsevier. Available from: https://www.elsevier. com/solutions/engineering-village/content/geobase.

37. Endnote. 7.7.1 ed: Clarivate Analytics; 2016.

38. Cook DJ, Mulrow CD, Haynes RB. Systematic reviews: synthesis of best evidence for clinical decisions. Ann Internal Med. 1997;126(5):376-80.

39. Moher D, Liberati A, Tetzlaff J, Altman D, Group P. Preferred reporting items for systematic reviews and meta-analyses: the PRISMA statement. Int I Surg. 2010;8(5):336-41.

40. Liberati A, Altman D, Tetzlaff J, Mulrow C, Gotzche P, loannidis J, et al. The PRISMA statement for reporting systematic reviews and meta-analyses of studies that evaluate healthcare interventions: explanation and elaboration. BMJ. 2009;339:b2700

41. Higgins JPT, Altman DG, Sterne JAC (editors). Chapter 8: Assessing risk of bias in included studies. In: Higgins JPT, Green S (editors). Cochrane Handbook for Systematic Reviews of Interventions Version 5.1.0 (updated March 2011). The Cochrane Collaboration, 2011.

42. Atkins D, Best D, Briss P, Eccles M, Falck-Ytter Y, Flottorp S, et al. Grading quality of evidence and strength of recommendations. BMJ. 2004;328(7454):1490

43. Diabetes Canada Clinical Practice Guidelines Expert Committee. Diabetes Canada 2018 Clinical practice guidelines for the prevention and management of diabetes in Canada. Can J Diabetes. 2018:42(Suppl 1):S1-S325.

44. American Diabetes Association. Standards of medical care in diabetes 2018. Diabetes Care. 2018;42(Supplement 1):S1-S159.

45. Margolis KL, Qi L, Brzyski R, Bonds DE, Howard BV, Kempainen S, et al. Validity of diabetes self-reports in the women's health initiative: comparison with medication inventories and fasting glucose measurements. Clin Trials. 2008;5(3):240-7.

46. Styne DM, Arslanian SA, Connor EL, Farooqi IS, Murad MH, Silverstein JH, Yanovski JA. Pediatric Obesity_Assessment, Treatment, and Prevention: An Endocrine Society Clinical Practice Guideline. J Clin Endocrinol Metab. 2017; 102(3):709-57.

47. Clinical guidelines on the identification, evaluation, and treatment of overweight and obesity in adults: executive summary. Expert Panel on the Identification, Evaluation, and Treatment of Overweight in Adults. Am J Clin Nut. 1998;68(4):899-17.

48. Mancini G, Hegele R, Leiter L. Diabetes Canada 2018 clinical practice guidelines for the prevention and management of diabetes in Canada: dyslipidemia. Can J Diabetes. 2018;42(Suppl 1):S178-S85.

49. Flynn JT, Kaelber DC, Baker-Smith CM, Blowey D, Carroll AE, Daniels SR, et al. Clinical practice guideline for screening and management of high blood pressure in children and adolescents. Pediatrics. 2017;140(3):e20171904.

50. Whelton PK, Carey RM, Aronow WS, Casey DE, Collins KJ, Dennison Himmelfarb C, et al. 2017 ACC/AHA/AAPA/ABC/ACPM/AGS/APhA/ASH/ ASPC/NMA/PCNA Guideline for the prevention, detection, evaluation, and management of high blood pressure in adults: a report of the American College of Cardiology/American Heart Association Task Force on clinical practice guidelines. J Am Coll Cardiol. 2018;71(19):e127-248.

51. Sattar N, Forrest E, Preiss D. Non-alcoholic fatty liver disease. BMJ. 2014; 349:g4596.

52. Karahalios A, Baglietto L, Carlin JB, English DR, Simpson JA. A review of the reporting and handling of missing data in cohort studies with repeated assessment of exposure measures. BMC Med Res Methodol. 2012;12:96.
53. Shea BJ, Reeves BC, Wells G, Thuku M, Hamel C, Moran J, et al. AMSTAR 2: a critical appraisal tool for systematic reviews that include randomised or non-randomised studies of healthcare interventions, or both. BMJ. 2017;358.

54. Thompson C, Schabrun S, Romero R, Bialocerkowski A, Marshall P. Factors contributing to chronic ankle instability: a protocol for a systematic review of systematic reviews. Systematic Rev. 2016;5(1):94

55. Whiting P, Savović J, Higgins JP, Caldwell DM, Reeves BC, Shea B, et al. ROBIS: a new tool to assess risk of bias in systematic reviews was developed. J Clin Epidemiol. 2016;69:225-34.

56. Deeks JJ, JPT H, Altman DG. Chapter 9: Analysing data and undertaking meta-analyses. In: Higgins J, Green S, editors. Cochrane handbook for systematic reviews of interventions version 510 (updated March 2011): The Cochrane Collaboration; 2011.

57. Virani S, Rentschler KM, Nishijo M, Ruangyuttikarn W, Swaddiwudhipong W, Basu N, et al. DNA methylation is differentially associated with environmental cadmium exposure based on sex and smoking status. Chemosphere. 2016;145:284-90.

58. Cowley M, Skaar DA, Jima DD, Maguire RL, Hudson KM, Park SS, et al. Effects of cadmium exposure on DNA methylation at imprinting control regions and genome-wide in mothers and newborn children. Environ Health Perspect. 2018;126(3):037003.

59. Mohanty AF, Farin FM, Bammler TK, MacDonald JW, Afsharinejad Z, Burbacher TM, et al. Infant sex-specific placental cadmium and DNA methylation associations. Environ Res. 2015;138:74-81.

60. Garner R, Levallois P. Cadmium levels and sources of exposure among Canadian adults. Health rep. 2016;27(2):10.

61. Lopez-Herranz A, Cutanda F, Esteban M, Pollan M, Calvo E, Perez-Gomaz B, et al. Cadmium levels in a representative sample of the Spanish adult population: The BIOAMBIENT.ES project. J Expo Sci Environ Epidemiol. 2016; 26(5):471-80.

62. Jacquet A, Arnaud J, Hininger-Favier I, Hazane-Puch F, Couturier K, Lénon M, et al. Impact of chronic and low cadmium exposure of rats: Sex specific disruption of glucose metabolism. Chemosphere. 2018;207:764-73.

63. Review Manager (RevMan). 5.3 ed. Copenhagen: The Nordic Cochrane Centre, The Cochrane Collaboration; 2014

64. Egger M, Smith G, Schneider M, Minder C. Bias in meta-analysis detected by a simple, graphical test. BMJ. 1997:315(7109):629-34.

65. IBM Corp. Released 2017. IBM SPSS Statistics for Windows, Version 25.0. Armonk: IBM Corp.

66. Report on carcinogens. Research Triangle Park, NC: National Toxicology Program, U.S. Department of Health and Human Services, Public Health Service; 2016.

67. Satarug S, Moore MR. Adverse health effects of chronic exposure to lowlevel cadmium in foodstuffs and cigarette smoke. Environ Health Perspect. 2004;112(10):1099.

68. Kim K, Melough M, Vance T, Noh H, Koo S, Chun O. Dietary cadmium intake and sources in the US. Nutrients. 2019;11(1):2.

69. Chunhabundit R. Cadmium exposure and potential health risk from foods in contaminated area, Thailand. Toxicol Res. 2016;32(1):65.

70. Arnold SM, Zarnke RL, Lynn TV, Chimonas M-AR, Frank A. Public health evaluation of cadmium concentrations in liver and kidney of moose (Alces alces) from four areas of Alaska. Sci Total Environ. 2006;357(1-3):103-11.

71. Järup $L$, Åkesson A. Current status of cadmium as an environmental health problem. Toxicol Appl Pharmacol. 2009;238(3):201-8.

72. Tinkov AA, Filippini T, Ajsuvakova OP, Aaseth J, Gluhcheva YG, Ivanova JM, et al. The role of cadmium in obesity and diabetes. Sci Total Environ. 2017; 601:741-55.

73. Edwards J, Ackerman C. A review of diabetes mellitus and exposure to the environmental toxicant cadmium with an emphasis on likely mechanisms of action. Curr Diabetes Rev. 2016;12(3):252-8.

74. Chen YW, Yang CY, Huang CF, Hung DZ, Leung YM, Liu SH. Heavy metals, islet function and diabetes development. Islets. 2009;1(3):169-76.

75. Zhou, B, Lu, Y, Hajifathalian, K, Bentham, J, Di Cesare, M, Danaei, G et al. Worldwide trends in diabetes since 1980: a pooled analysis of 751 population-based studies with 4.4 million participants. The Lancet. 2016; 387(10027):1513-30

\section{Publisher's Note}

Springer Nature remains neutral with regard to jurisdictional claims in published maps and institutional affiliations. 